\title{
Intragastric balloon: use of prophylactic nystatin for the prevention of fungal colonization
}

\begin{abstract}
Introduction: The intragastric balloon is the medical treatment indicated for patients with overweight and obesity, it's safe and effective with great results all over the world. But in some cases, fungal colonization was observed and can be promoted early removal. So, this article has evaluated the effectiveness of the use of antifungal (Nystatin) to prevent the appearance of fungi in silicone. Patients (120) were divided into two groups: 50 milliliters of nystatin (100,000 IU/ML) mixed with saline solution with Methylene Blue in the IGB filling and IGB filled with saline solution and Methylene Blue. Results: The prevalence of fungal colonization was $9.25 \%$ and $19.15 \%$ for the group with and without antifungal respectively. There was no significant difference in outcomes between gender and age. Conclusion: Nystatin into the saline solution in the IGB filling reduced the fungal colonization.
\end{abstract}

Keywords: obesity, fungal, nystatin, intragastric balloon, fungal colonization
Volume 9 Issue 5 - 2019

\author{
Bruno Q Sander,' Santos Paiva D,' Marcelo \\ Sander,' Jimi Scarparo, ${ }^{2}$ Felipe Matz, ${ }^{3}$ Flávio \\ Ramos, ${ }^{3}$ Alberti luiz ronaldoa ${ }^{4}$ \\ 'Sander Medical Center, Brazil \\ ${ }^{2}$ Scarparo Scopia, Brazil \\ ${ }^{3}$ EndoDiagnostic, Brazil \\ ${ }^{4}$ Universidade Federal de Minas Gerais, Brazil
}

\begin{abstract}
Correspondence: Bruno Queiroz Sander, Universidade Federal de Minas Gerais, Avenida Bernardo Monteiro, Belo Horizonte, Minas Gerais, Brazil, Tel +542235475903, Email brunosander@hotmail.com
\end{abstract}

Received: October 18, 2019 | Published: October 31, 2019

\section{Introduction}

The intragastric balloon (IGB) has been used for more than 20 years in Brazil as an endoscopic method for assisting weight loss, and some intercurrences were observed during more than 10,000 procedures performed. ${ }^{1}$ One of these intercurrences is the presence of fungi in the IGB, increasing the friability of the silicone and inducing the premature rupture of the IGB, as well as gas hyperinflation..$^{2-4}$ The aim of this study was to evaluate if the use of Nystatin can decrease the prevalence of fungal colonization cases in IGB devices.

\section{Methodology}

To evaluate the effectiveness of the use of antifungal (Nystatin), diluted in intragastric balloon filling saline solution, in order to prevent the appearance of fungi in silicon, 120 patients (76.7\% women) who underwent adjustable intragastric balloon Spatz3 throughout the year 2017. Patients were divided into two groups by randomized clinical trial: 60 patients had 50 mililiters of nystatin (100,000 IU/ML) mixed with saline solution with Methylen Blue in the IGB filling (Test Group) and the other 60 patients had their IGB filled with saline solution and Methylene Blue (Control Group). The design of this study was double masked. Only the nursing team knew which patients had received antifungals in the filling of the balloon.

The initial volume of IGB filling in all patients was $700 \mathrm{ml}$. Initial BMI started at $27 \mathrm{~kg} / \mathrm{m}^{2}$ and IGB maximum period implant was 12 months. When the IGB was removed, the Endoscopist described whether there was fungal colonization on the silicone surface and, when there was, divided the colonization on the silicone surface in 4 stages: less than 10\% (insignificant), between 10\% and 25\% (light), between 20 and 50\% (moderate) and more than 50\% (accentuated). When there was insignificant colonization (up to $10 \%$ ) it was described as normal in the database. All ethical guidelines established by the Research Ethics Committee were strictly followed, and all patients signed the Informed Consent Form.

\section{Results}

Were excluded from the final analysis 19 patients (15.84\%): of these $2(1.66 \%)$ due to early removal, $15(12.5 \%)$ did volume adjustment during the IGB and $2(1,66 \%)$ balloon spontaneous deflation or leakage. The sample was young adults (Age: $30.49 \pm 5,36$ ) and the mean weight loss was $20.64 \pm 16.8 \mathrm{~kg}$. Among the 101 patients analyzed, 54 had antifungal in the IGB and 47 only saline and methylene blue. In the group with antifungal the incidence of fungal colonization was $9.25 \%(\mathrm{n}=5)$. In these, $4(80 \%)$ presented light colonization and $1(20 \%)$ with moderate colonization. In the Control Group the prevalence of fungal colonization was $19.15 \%(\mathrm{n}=9)$. In these $4(44.5 \%)$ presented light colonization, $3(33.3 \%)$ with moderate colonization and $2(22.2 \%)$ with accentuated colonization. There was no significant difference in outcomes between men and women and. ${ }^{5}$

\section{Discussion}

During the IGB insertion procedure, contamination may occur through the oral cavity, or even by IGB manipulation. The device induces a delay in gastric emptying, and this mechanism may facilitate fungal colonization ${ }^{5}$. In addition, fungus like Candida colonize and form biofilms more easily in silcone. ${ }^{6}$

The use of mixed nystatin to the saline solution in the IGB filling reduced the fungal colonization in the silicone coating by half, demonstrating that this practice has a positive effect with low cost and significant difference in fungal prevention. However, even associated with IGB friability, fungal colonization does not prove to be of such importance since balloon spontaneous deflation or leakage corresponded to only $1.66 \%$ of the total initial sample and the 14 
patients who presented fungi in the IGB $(13.86 \%)$ did not present any clinical symptoms.

\section{Acknowledgements}

None.

\section{Conflicts of interest}

The author declares that there is no conflict of interest.

\section{Funding details}

None.

\section{References}

1. Sander BQ, Sander MQ, Paiva DS, et al. Intragastric Balloon: A Large Brazilian Multicentric Study Over 10,000 Cases and 20 Years of Experience. Adv Res Gastroentero Hepatol. 2019;12(3):4.
2. Coskun H, Bozkurt S. A case of asymptomatic fungal and bacterial colonization of an intragastric balloon. World J Gastroenterol. 2009;15(45):5751-5753.

3. Kotzampassi K, Vasilaki O, Stefanidou C, et al. Candida albicans colonization on an intragastric balloon. Asian $J$ Endosc Surg. 2013;6(3):214-216.

4. Neto MG, Silva LB, Grecco E, et al. Brazilian Intragastric Balloon Consensus Statement (BIBC): practical guidelines based on experience of over 40,000 cases. Surg Obes Relat Dis. 2018;14(2):151-159.

5. Rajablou M, Ganz RA, Batts KP. Candida infection presenting as multiple ulcerated masses. Gastrointest Endosc. 2007;65(1):164-166.

6. da Silveira LC, Charone S, Maia LC, et al. Biofilm formation by Candida species on silicone surfaces and latex pacifier nipples: an in vitro study. $J$ Clin Pediatr Dent. 2009;33(3):235-240. 